\title{
Competition, contest and the possibility of egalitarian university education
}

\author{
Damian Cox
}

Bond University

dcox@bond.edu.au

\begin{abstract}
Competition and contest underpin academic life in many ways, not all of them constructive or valuable. In this paper I make a start on the task of distinguishing valuable academic competition from its opposite and suggest reforms of academic institutions that would diminish the prevalence of destructive competition and approach more nearly the egalitarian goal of treating all members of the academic community-especially, but not only, students-as equally valued and equally deserving of respect. To do this, I develop a distinction between two kinds of competition: tender competition and rank competition. I analyse the illusion of meritocracy in terms of them. My principal recommendation for university pedagogical practice is to eliminate grading of student work and replace grading systems with a system of demanding pass/fail assessments.
\end{abstract}

\section{Key words}

assessment, competition, egalitarianism, meritocracy

\section{Introduction}

What would an egalitarian future for higher education look like? The question is generally answered in terms of access to higher education institutions and the equality of preparation for entry into them. For example, debate in the United States centres around the role of Student Assessment Tests (SATs, formally known as Student Aptitude Tests) in college and university admissions. Since SAT scores correlate strongly with Social and Economic Status (SES) and account for only a tiny percentage of student achievements in higher education (on some measures, they 
capture only $5 \%$ variance in first year results with no significant correlations in later years), they are targeted for criticism by those interested in fair access to higher education (see Guinier 2015 for a powerful version of such criticism). In other countries, access to higher education varies according to the quality or focus of schools or other aspects of a child's learning environment. The urgent task here is to understand the conditions under which fair access to opportunity is established and what institutional, social, economic and cultural features of a community undermine or enhance fairness of opportunity.

The issue of access is vital, and I do not wish to underplay its significance. But I want to ask another question; one of immediate concern for the practice of institutions of higher education. What would it be like to be an egalitarian university? What would it be like to attend an egalitarian university? How would such a university not only select students, but treat them once they are enrolled? How would they be assessed? How would they be taught? What features of the institution work against egalitarian principles and which help reinforce them?

To answer these questions, I am going to defend an account of egalitarian practice in education. The chief value of egalitarianism is that it secures equality of respect within a community, in this case an educational community. Other virtues of a university-things such as intellectual openness, integrity, curiosity, rigour-are obviously to be valued. Egalitarian concern for equal respect ought to be in this list. This is primarily because secure, substantive equality of respect is fundamental to the flourishing of individuals. Egalitarianism matters because, in general, people live the best lives when they do so in an environment that accords them genuine equality of respect (formal or notional equality of respect is insufficient-). In my view, particular features of egalitarianism - things such as fair equality of opportunity, equality of political value, approximate equality of social and economic lifeprospects and life-outcomes-are principally valuable because they enhance individual lives, grounding the security of individual self-respect and evading the psychologically corrosive effect of living cheek by jowl with one's socially defined betters. (In the $21^{\text {st }}$ century, everyone lives cheek by jowl with their socially defined betters.)

What are the egalitarian principles that ought to drive our practice, both in general and in educational settings? What is the relationship between egalitarianism and meritocratic practice? Does being an egalitarian mean abandoning the struggle to achieve excellence? Unsurprisingly, I wish to answer this last question negatively. 
Nonetheless, I will propose quite radical changes in practice -in terms of instruction and assessment and university culture-to bring universities into line with egalitarian ideals.

The key feature of my argument is the claim that egalitarian principles are not opposed to the search for excellence, but are opposed to a particular sort of competition, which I will call 'rank competition'. What undermines the egalitarian potential of universities is their lazy substitution of rank competition for the struggle for excellence. In rank competition, students are pitted against each other rather than challenged with an external standard or goal. The motivation underpinning rank competition is the drive to sort students out and rank them from best to worst, so that both the students themselves, and anybody who cares to inquire, knows and invests considerable value in knowing - not whether a student achieved a level of competence or excellence, but where they came in their class, what their grade point average was, how much better they were than the average. Much of my essay is concerned to make the case against rank competition in general, before applying it to the case of higher education ranking.

\section{Egalitarianism, meritocracy and competition}

A great deal of philosophical work on the concept of egalitarianism, following John Rawls' (1971) and Ronald Dworkin's (1981a, b) extraordinarily influential work in the second half of the last century, concerns distribution of social and economic goods. Education is a good, both a social good and an economic good, and justice requires its egalitarian distribution. According to both Rawls and Dworkin, this presupposes a principle of fair equality of opportunity (roughly, that any two people of equal talent and willingness to work should have equal access to institutions of education and equal chance of success within them). The differential rewards that come from educational success are governed by separate principles of justice. Here Rawls and Dworkin parted ways. Rawls proposed a principle of distribution - his famous difference principle - which limited differential economic and social rewards to those that benefit the least well off. Dworkin proposed a principle of compensation. Dworkin began a tradition of what has come to be called luck egalitarianism. Roughly, according to luck egalitarians, any differential rewards should reflect non-luck-based differences between individuals (principally ambition, determination and effort). Luck, such as the social position of one's birth, should play no role in the distribution of social and economic goods and where luck cannot 
be, or has not been, eliminated the unlucky are owed compensation for their bad luck. ${ }^{1}$

This is not the place to embark upon an examination of the complex history of the discussion Rawls and Dworkin kicked off. I want, however, to point out an obvious limitation of their approach to the question of egalitarian justice. Theorising the distribution of goods misses out on a prior and more fundamental question: what sort of goods ought to be produced and distributed in the first place; in particular, what kinds of social goods ought to be available for distribution? It would be a mistake to create essentially hierarchical social goods (esteem factors, for examplemore on these later) and puzzle over the principles that ought to govern their distribution in an egalitarian society. A society would be more coherently egalitarian if it were to exclude such goods in the first place.

Fixation on economic distribution tends to hide this problem. Economic goods are essentially fungible and interpretatively open. If a person comes out on top in a winner takes all economic competition and walks away with a packet, the social meaning of the win is not settled. The winnings can be swapped, given away, taxed, or in another way redistributed; they can be regarded as a mark of justified pride or derided as the ill-sorted gains of a valueless, corrupt or in some other way unworthy system. They might be a source of shame; they might be seen as the wages of luck. Distribution of honours cannot be like this however. They cannot be swapped; their interpretation is difficult (though not impossible) to resist or revise. They carry their social meaning on their sleeve, as it were. Social goods also can be, and often are, the product of sub-groups within society. Cultural appropriation is a matter of treating culturally specific goods as if they were properly available for general distribution; in effect, it is to act as if a socially specific group can be joined by anyone with the audacity and assumed privilege to attempt it. It is thus a mistake to treat all social goods as goods to be distributed according to some egalitarian principle of distributive justice. Let me call social goods that ought not be created and distributed in this way 'inegalitarian social goods'. According to the picture of egalitarianism I am setting out, some inegalitarian social goods ought to be eliminated, minimised or problematised (honours, rank, privileges); others ought to be preserved and respected (goods definitive of particular social identities).

\footnotetext{
1 Dworkin (1981) distinguished between brute luck and option luck (the luck one is exposed to in virtue of one's free choices). He argued that only brute luck ought to be eliminated, as far as reasonably possible, in the distribution of social and economic goods.
} 
David Miller (1999) and Michael Walzer (1983), writing in the roughly same period as Rawls and Dworkin, recognised this general lacuna in theories of distributive justice. They both suggested, in different ways, a picture of equality that concerned itself with the social markers of equality of respect. They imagined an egalitarian community in which economic differences do not translate to social privileges of rank and class; where economic position does not influence social position and the sorts of social relationships one is able to develop. Perhaps this sounds reasonable, though I doubt that in practice it is at all possible to isolate economic privilege from social privilege. In Walzer's 'Society of Misters', rank and class play no social role; every person is owed the same basic social respect regardless of their occupation, attainments, origins. However, I believe we need to think through the social egalitarian task more fully than did either Walzer or Miller. The idea of equal respect and consideration is, by itself, insufficient for the task at hand. That is because many societies and many institutions-more so now than in the middle of the $20^{\text {th }}$ century-are hypercompetitive and suffer from delusions of meritocracy.

To explain what I mean by a hypercompetitive society, I will distinguish between two kinds of competition. Competition can be organised around a quest for a particular, valued outcome. For example, an institution plans a new cultural museum. A standard way to proceed is to initiate an architectural competition. In such a competition, architectural firms from around the world develop philosophical approaches, plans, and models in an attempt to satisfy the needs and wishes of the institution. They are likely to go beyond the brief furnished by institution and search out inspiring and richly imagined design solutions, seeking to understand the purpose, cultural and physical environment, the most profound wishes of the community, and so on. The result is a competition in which one design is chosen, generally by a committee. The decision may be a foolish one; but at its best it is the exercise of genuine propriety and cultural knowledge. Call this kind of competition 'tender competition'. It is widely employed, and for all its fragility, it is probably the most effective and appropriate way of determining such things as design contracts. It is competition between objects and proffered services.

I think that tender competition is an excellent way of procuring valued goods. Consumers, in effect, place market goods in tender competition when they shop around. In the absence of tender competition, the production of goods tends to slide into shoddiness and unimaginativeness and the provision of services tends to become complacent and indifferent. When people praise market competition and capitalism's capacity to make lives better, they are almost invariably talking about 
tender competition. Tender competition in capitalist economies improves services, generates innovation, fosters customer care. If one company outcompetes another in tendering for customers, they generally do so by delivering a better product. (This is so whether the customers are investors tendering for a financial product or individuals and groups tendering for goods and services.) The relationship between tender competition and delivery of better products is contingent and patchy. But the success of capitalism rests on it nonetheless. Market competition has numerous facets, and I do not wish to oversimplify the complexity of it or the problems it both generates and encounters. My claim is simply that, to the extent that market competition delivers on the task of improving people's lives, it does so through one form or another of tender competition. If egalitarians are interested in prosperity and the excellence of goods and services available to ordinary people, if they are concerned to avoid a procrustean nightmare of universal mediocre treatment, they had better not seek to undermine tender competition and its ubiquity in economic life.

But there is another sort of competition, one I have already introduced. In rank competition, the point is not to discover a best available product or service, but to sort people into ranks. Sporting competition is the basic model. A sporting event, say a one hundred metre sprint, is not an attempt to procure anything. It is an attempt to sort runners into fast, faster, fastest (equivalently, slowest, slower, least slow). The attainment itself is of no value whatsoever. This is essential to the ludic character of sport. In an absolute sense, nobody cares how fast Usain Bolt runs. He doesn't care. Bolt is slower than a cocker spaniel over fifty metres. I doubt this unsettles his selfesteem. ${ }^{2}$ What we care about, what Bolt cares about, what the Olympic committee cares about, what his fans care about, is that during his career he ran faster than his competitors. To call him a fast runner just is to call him faster than most (or all) others, over an artificially specified distance. (Imagine a sprinter who would leave Bolt in his wake over 300 metres, but is uncompetitive over 400 metres. Nobody is going to much care about him; he never gets to compete over his ideal distance. He would be, officially, a loser.) Bolt has been a magnificent athlete and is widely and properly admired, but not, it turns out on close inspection, because of the speed of his running. He is admired because he won many races and it turns out that speed is just the thing needed to win sprinting races. Bolt recorded faster sprint times than Jesse Owens, but he is not generally considered the greater athlete because of that.

Actually, I am making this up. I have no idea if a cocker spaniel could outrun Usain Bolt. And I don't care. That, of course, is my point. 
The comparison is ill-founded. Both Owens and Bolt were champions of different eras, with different training regimes and techniques. They were champions because they won races. Who would win a fantasy sprint between them is a rather odious question; certainly, it is a pointless one. The fact that fans might well be tempted to ponder it nonetheless demonstrates the ubiquity of the conception of sport as a ranking exercise.

Sporting competition is about establishing rank for activities that simply don't matter in and of themselves. This is probably its saving grace, and the key to its cultural success. An ordinary person can lose at sport without substantial loss. The losses are all positional, social and temporary. A black belt judo exponent gets thrown repeatedly by a novice; the novice is unpracticed, but faster, stronger, more intuitive. The expert is embarrassed, perhaps humiliated, but there is the consolation (if it can be brought to mind) that, after all, the ability to throw a grown person over your shoulder is not an important matter. There is pretty much no call for it outside of a Tatami mat. As a sport, it is just something people do to see if they can do it better than other people. And that's it.

Outside of professional and elite sport (both complicated affairs), and if pursued with the right sort of mind-set, in the right sort of social environment, sporting competition is reasonably harmless. The right sort of mind-set is one in which its essential meaninglessness is readily available to reflection. Sporting contests give the temporary illusion of high stakes, and that is both thrilling an invigorating. But it is an illusion. After the event - it can take a long time-axiological reality seeps back in and winning and losing are recognised for the intrinsically empty things they are. The right sort of social environment is one in which this intrinsic meaninglessness is reflected in an abiding lack of seriousness with which winning and losing are treated. Things can begin to matter very much when social standing, friendships, social and economic rewards of all kinds come to depend on the outcome of sporting contests. These are situations in which sporting competition is an ugly, dire affair; when it becomes anything but harmless.

Sporting competition is interesting, but is its relevance to the egalitarian principles of institutional practice? It lies in the fact that, in many societies, rank competition has become the defining characteristic of contemporary social life. Much of our professional and social lives have become like a sport, but a sport where outcomes really matter and excellences involved are intrinsically valuable. Millennial life involves endless ranking: ranking best movies, best cheeses, best 1980s sit-coms. We 
collect Facebook likes (some of us) and treat them as quasi-competitions. When an acquaintance's post is smothered in likes, while your picture of your new kittens rates a desultory few, it is as if you have lost out in some competitive endeavour. ${ }^{3}$ Even more strikingly, very many professional lives are subject to endless ranking competitions. Doctors can be ranked by their success rates; lawyers by their court victories; academics by their h-indexes. In universities, the practice of measuring and ranking is extreme. Consider professional academics. First, they are measured: publications, output rank (is the publication in a top tier journal?) citations, teaching evaluations, esteem factors, and so on. Second, the measures are ordered, either explicitly or implicitly, to distinguish successful academic competitors from the alsorans. This is largely done in the name of meritocracy. Let me therefore turn to the concept of merit and the idea of a meritocratic institution.

The principal difference between tender competition and rank competition is that tender competition takes as its object specific goods or services, whereas rank competition takes as its object persons and their status. Meritocracy is the systematic conflation of the two. Some feature of a person is taken to be valuable: say, their skill at conducting EEG experiments. A competition is set up in which we search for the most skilful available experimenter for a project. So far, this is tender competition. It is a competition for a service, seeking out the best available service for a valuable purpose. Now we expand our competition and devise a scale for judging the degree of an experimenter's skill. Experimenters are rated on a ten-point scale from 10 (peerlessly good) to 0 (has to be shown how to switch on the machine). We set up a virtual competition between all potential experimenters $(\mathrm{PhD}$ students, research assistants, visiting professors, and so on). Then we devise a way of rewarding and honouring the winners of this competition for their display of merit. We have converted a tender competition into a rank competition. The justification for this is that it makes the goals of tender competition easier to reach. Instead of considering who would be a good fit for our experimental project, and looking, we can consult a list. Start with the 10s. If none of them are available (or there aren't any), go to the 9s. Continue until you discover the highest ranking experimenter available. Perhaps rank competition has this benefit; perhaps it eases the path to tender. But it also diminishes the professional lives of everybody subject to it: they become the bearer of a number and their professional standing is determined (to a substantial extent) by this number. Professional rank competition is simply a lazy way of achieving the

3 This is taken to its logical conclusion in 'Nosedive', an episode of the science fiction series Black Mirror (2017). In Nosedive, people are ranked by their social media likes and their rank determines access to a vast array of social and economic goods, necessities as well as privileges. 
perfectly legitimate goals of a tender competition, but one that has invidious side effects and diminishes the professional lives of those subject to it. Merit (in this case experimental excellence) becomes not something to be tendered for (or to be encouraged, fostered, enabled, developed); it becomes a tool for status competition.

Merit ranking practices needn't be intentionally directed at status competition, of course. It is possible to rank people relative to non-comparative criteria and for this ranking to issue in no tendency to make interpersonal comparisons, and thus no tendency for people to indulge in competitive status mongering. But this is a heroic denial of what is obviously present in the thing itself. A rank is an ordering of one person relative to another. It might also be an ordering of that person relative to noncomparative standards of one sort or another; but it is perforce a comparative measure. When such things latch on to privileges and rewards, competition is inevitable, and this competition is, first and foremost, a competition for rank. Status, rewards, honours, privileges, comparative self-satisfactions: all these things follow in the wake of a ranking. Non-competitive rankings are an implausible and, I suspect, rare phenomenon.

Merit ranking immiserates the majority: the also-rans in the merit race. Competition for merit scores produces copious, uncontrollable forms of system gaming. Under merit ranking, people are motivated by external goods (a high score and the status and prizes that come with it) rather than internal goods (excellence itself). In an environment dominated by rank competition, success largely goes to those best at playing the merit game. (You generally need to be good at what you do to be good at the merit game, but you also need to be much more than good; you need to be good at bettering others on criteria of an institution's choosing.)

Another-completely obvious-problem with rank competition is the problem of mismeasurement. Rankings require measurements; but most things of intrinsic value are resistant to accurate and reliable measurement. ${ }^{4}$ We wish to measure a person's research quality. Let's count the number of their publications and the prestige of their publications. (What is the rejection rate of the journals they published in? A 95\% rejection rate means that their work is better than that of at least $95 \%$ of other academics. (Sure.) What is the Scimago ranking of the journals? What is the overall h-index of the journals?). Let us count the patents their work has yielded; the number of citations they have received; and the number of associated esteem factors.

4 Jerry Muller (2018) provides a searching examination of this phenomenon, in university settings and elsewhere. 
(Has the researcher been invited as keynote speaker to highly ranked conferences? How many prizes and awards and fellowships have they won? How many competitive grants have they scored?). Then let us agglomerate all this into a number. The resulting figure will be a measure of research quality. We can then rank everybody in our institution by this number. (Perhaps researchers should wear a badge displaying it whilst on campus). Whatever else one might think of this process, the measure will be at best only loosely correlated with the quality and value of research undertaken; and this only on the assumption that there are uncontested, meaningful, precise, quantifiable, and enduring standards for such things in the first place.

A hypercompetitive environment, on my definition, is one that immerses us in numerous, highly significant, practically unavoidable rank competitions. In a hypercompetitive environment, personal worth is all too readily mistaken for success in rank competitions. Meritocracy, again on my definition, is the process of confusing the competitive pursuit of what is valuable with the competitive pursuit of rank. Instead of seeking outcomes of intrinsic value, people in meritocratic environments come to seek measures of comparative merit; people are manipulated into playing the merit game. The concept of meritocracy was first introduced as satire and, on my definition, it deserves a return to satire. ${ }^{5}$ What, then, is the appropriate egalitarian response to this situation? I believe that egalitarian professional practice consists primarily in a determination to do away with every last vestige of ranking within the practice and replace it with alternative ways of encouraging and ensuring excellence. It is a determination to eliminate the inegalitarian creation of privilege through rank.

\section{The egalitarian university and student experience}

I have drawn out the nature of rank competition and its drawbacks. I have tried to show how the very idea of such a thing is thoroughly inimical to the egalitarian business of treating others as deserving of equal respect and equal social standing. I have used the example of professional university researchers to do this; and to illustrate the horrors of (uncertain, contested, ill-measured, gamed) meritocracy. In an egalitarian university, academics would be free to cooperatively pursue what is

\footnotetext{
5 The term 'meritocracy' was coined for satirical purposes by Michael Dunlop Young (1958). The term has since passed into a nonchalant, unironic acceptance. A public appeal to meritocracy is generally expected to evoke comfortably nodding heads.
} 
valuable in their practice without the distractions and psychological deficits of rank competition. However, my main interest lies with the experience of students entering university, with their educational, social and personal experience. From an egalitarian point of view, students in most tertiary institutions are treated at least as badly as professional researchers. They are measured and ranked to within an inch of their lives. These measures and rankings are the fundamental goods purchased by all their efforts (and money). It is summed up in their academic transcript and grade point average. In many institutions, including my own, students are subjected to continual, involuntary, life-shaping rank competition. For example, at the conclusion of every subject at my university, a list is drawn up of the best in class and the upper echelon of students who keep them company. The best in class is presented with a prize on prize night (it could be a monetary prize or merely a certificate). Others are sorted into Dean's List students (a good grade) and Vice Chancellor List students (a very good grade). They are paraded in front of their parents; they get a photograph with the Dean; they have a party afterwards. Those who don't make the list tend not to come.

An egalitarian institution simply has no place for such a thing as prize night. There are more fundamental issues to address however. Rank competition can be explicit-as in 'best in class' prizes and the like-and they can be implicit. An implicit competition is set up when the materials for ranking are assembled, significant goods are associated with high rank (e.g. entry into postgraduate study; employment prestige such as in a high-ranking law firm, or indeed, employment at all), and everyone subject to the ranking is aware of the relation between rank and success. Such a concatenation of circumstances makes competition inevitable. In discussing anxiety and stress with third year law students recently, I was struck by the extent to which they considered each other rivals for academic rank. Successful completion of their studies was not their concern. These were hardworking, contentious students; they were confident of graduating in good time and with a good education in the law. However, they realised-or thought they realised-that their chances of success depended upon them not doing well per se, but doing substantially better than their fellow students. This kind of competition can play out in game-playing (e.g. misleading fellow students about the content of missed lectures) and a pressure to cheat; but mostly it results in a stressful, unnecessarily alienating experience where people who ought to be one's friends (and generally are one's friends) are also rivals and competitors; the people whose higher rank may well undermine one's own efforts at a career in law. The reason for this is that 
success in the profession is thought to depend upon collecting a suite of esteem factors (prizes, wins in mooting competitions, 'best in class' awards, valedictorian speeches) together with a grade point average well above those of one's rivals.

My conclusion is that, in an egalitarian university, not only will prizes and other esteem factors-explicit competitive rankings-be avoided, so will grade point averages. A grade point average is a single marker of academic rank. Even if the grades are arrived at by criterial assessment, even if they are not broadcast to the community, grade point averages, or their equivalent, come to represent a student's academic rank. This may seem innocuous, but when prestige and success depend on academic rank, rank competition is inevitable. And it is corrosive of a university's mission and of student wellbeing.

There is but one general assessment method that predictably undercuts the incessant ranking of student life, and that is a demanding pass/fail system. ${ }^{6}$ Such a system eliminates distinctions between levels of performance and replaces it with a requirement to meet stringent and relevant standards of attainment. It has three main advantages. First, it generates results that match the mission of universities. Universities certify graduate competencies. If a student has passed a subject, the university certifies - or should certify - that the student is fully competent in the subject and has fully met the learning outcomes of the subject. From the point of view of employers, certifying graduate competencies is a university's primary task. (Of course, the employer's point of view is not the only, or dominant, one amongst university stakeholders.) A differential grade system (As, Bs, Cs, etc.; producing grade point averages) tends to fail in this respect. Students with mere passing grades are often not fully competent in the fields in which they have studied. A doctor who has managed nothing above a pass in all their medical studies is hardly guaranteed to be a good fit for a career in medical practice. Of course, differential grade assessment can be framed so that, in principle, passing a subject establishes full competency in it. But the general tendency is to let grade point averages do the work of distinguishing between promising candidates for a career and those not fully up to the task. This allows institutions to pass students who are not fully competent in a subject so as to give them a chance to improve over the course of their degree

6 Demandingness is required for two reasons: to match the certification aims of the university (see below); and to maintain appropriate levels of commitment from students. A subject in which everybody expects to pass with even minimal levels of effort, and in which there is no other reward for effort, is a subject which risks losing student respect and diminishing levels of student commitment. 
without repeating subjects. (Requiring successive repeats is a relatively expensive option.) A better system would certify exactly what is demanded of universities: that a pass is a signal of genuine competence.

The second advantage of a demanding pass/fail assessment system is that it facilitates cooperative learning among students. ${ }^{7}$ For example, some of the best university teaching is done by organising students into teams and having them work together on projects. This is an awkward fit with differential grading because students are apt to complain about the averaging of results produced when team projects are assessed. The best students feel themselves brought down by weaker team members, and while weaker team members benefit, they are also, often, painfully aware of the residual resentment that attends this benefit. If, on the other hand, students work together to produce a passing grade-one that is nonetheless quite demanding - they have every incentive to pull together and not resent the contributions of any of their members. Of course, team tensions are not thereby eliminated, and the problem of free-riding remains. But such problems are always with us in cooperative endeavours.

The third and most significant advantage of a demanding pass/fail assessment system is that it reduces the tendency to rank students. Of course, teachers and students remain aware of the fact that some students are stronger performers than others. A pass/fail assessment system is not based on a pretence that all students are equally good at what they do. Rather, it is based on the conviction that representing the order of ability and attainment is not the official business of the university. For example, it is generally obvious to me who the strongest students in my class are. They ask lucid questions and catch onto ideas quickly; they write with clarity and purpose; they notice the difference between insightful, pedestrian and merely fanciful ideas; and so on. As a teacher, however, I pay this little mind except to ensure that the best students are not bored and frustrated, and the least able students are not lost and confused. Apart from that, I don't particularly care of a student whether they are among the best in class or anything else. In a very real sense, this is not my business. I am a teacher, not a talent scout.

7 See Guinier (2015), Chapter 6 for a telling example. Guinier challenges received versions of meritocracy by advocating a revised concept of merit: democratic merit. While I see merit (apologies) in the idea, I also think that it is prone to misuse and the introduction of yet more systems of ranking. I argue that it is better to do away with the idea of merit competition altogether. 
Student experience in a university that eschews prizes and myriad rank competitions, that marks on a pass/fail basis, that demands full competence from students, is one in which students are treated with perfectly equal respect and with equal standing in the academic community. Students are judged on their satisfaction of required standards of competence alone, and comparison with other students is relatively muted. Students at such a university would be able to treat each other as genuine equals; not in ability, but in standing within the community. Of course, humans are inexhaustibly hierarchical creatures and an egalitarian institution is never going to eliminate all tendencies to odious comparison and the formation of dominance hierarchies. Students who pass easily and often may be tempted to lord it over those who pass only with effort and not invariably. The point is to mute these tendencies, to not reinforce them, to not glory in them.

Let me conclude my discussion by examining a range of objections to my proposal. The first is derived from a question of motivation. No matter how demanding a pass/fail system is, no matter how accurately it tracks accredited competencies, it threatens to generate a levelling of ambition. What incentive is there in such a system for the best students to stretch themselves and realise their potential? Implemented badly, such a general assessment system would leave the most able students under-motivated. So, the question is, what motivates the best students to realise their potential? Is it beating weaker students to a prize? Perhaps. But that only introduces the need to establish and bring to the forefront of the university the internal goods of study. In an egalitarian university, excellence must be internally motivated. The best students are also the best motivated students; the students with the best concept of what is good and valuable in what they are learning. And the university's task is to help them see all this and realise the relevant internal goods with clarity and vigour. For example, the best philosophy students, by definition, will love doing philosophy, not beating up on students who aren't so good at it. As motivation, ranking systems take the lazy and intellectually corrupt path of substituting the external goods of beating others - of gaining status over them and success at their expense-for the internal goods of a practice. It is the fundamental business of a university to resist this corruption.

A second objection to egalitarian practice in universities has to do with justice. It might seem that students who excel deserve reward, and artificially restricting the availability of these rewards does them an injustice. On Aristotle's conception of justice, a just institution would be one that distributes rewards and honours by desert: each person in the institution would gain what they deserve and no person 
would gain more or less than they deserve. Egalitarian practice fails to track desert, so the objection goes. This way of thinking is mistaken, however. It would certainly be unjust to manipulate a differential grade system so that all students came out with the same grade, no matter the level of their achievement. Doing so would be misleading; it would be a pretence of equality where none exists. However, a demanding pass/fail system is not misleading in this way. It does not set out to track exact levels of achievement, but to indicate whether core competencies have been achieved. Were there a differential grade system, students who do the best work would deserve the best grade. But in a demanding pass/fail system, students who demonstrate the appropriate competencies deserve to pass and those who do not deserve to fail. In such a system, the best students are not owed a superior rank because the system is not in the distribution of rank business. I can't see a reason to think that there is a natural, system independent, right to laud one's achievements over others; so it does not seem at all unjust that people be deprived of a system in which they can do just that.

Yet another objection comes from university stakeholders. Employers like to know job applicants' graduating rank or some approximation of it because they wish to employ the best available graduates. Failure to furnish such a rank artificially deprives stakeholders of information they expect and want to get. This is also true inside universities. Graduate programs look to grade point averages and similar metrics to help them decide who would be suitable candidates for graduate degrees. In both cases, the response is similar. Employers have a right to know whether a graduate is competent, and in what. Outsourcing further selection processes to universities is, mostly, a lazy and counterproductive way of choosing who to employ. There are many alternative selection processes available to employers and they should use them. Graduate programs, deprived of grade point averages or honours degree rank, would have to rely on independent measures: writing samples, references, interviews. All of these are plainly superior (if time-intensive) ways of determining graduate student admissions.

Finally there is a potential problem with my proposal to do with the best interests of students. At present, egalitarian institutions would likely be cast adrift in a hypercompetitive environment. They would not integrate neatly into such environments and would, perhaps, ill-prepare students for life in them. This may reveal a utopian characteristic of my proposal, but not necessarily. Of course, egalitarian institutions work best in egalitarian environments. And, unsurprisingly, I hold that egalitarian environments allow people to live happily and peacefully in 
ways that hypercompetitive environments cannot approach. Nonetheless, there is much to be said, even in a hypercompetitive world, for a safe and nurturing space in which young people can develop their best selves and learn their craft. That is not a hypercompetitive university; it is not a place where the clever and assertive lord everyone else. It is a place where all students enjoy equal standing in their academic community. There is reason to be confident that, even in a hypercompetitive environment, students in an egalitarian university would flourish.

\section{References}

Black Mirror (2017) Television series. Distributed by Netflix. Episode 1, season 3, directed by J Wright.

Dworkin, R (1981a) What is equality? Part I: Equality of welfare. Philosophy and Public Affairs, 10(3), pp. 185-246.

Dworkin, R (1981b) What is equality? Part II: Equality of resources. Philosophy and Public Affairs, 10(4), pp. 283-345.

Guinier, L (2015) The tyranny of the meritocracy: Democratizing higher education in America. Beacon Press, Boston, MA.

Miller, D (1999) Principles of social justice. Harvard University Press, Cambridge, MA.

Muller, J (2018) The tyranny of metrics. Princeton University Press, Princeton, NJ.

Rawls, J (1971) A theory of justice. Oxford University Press, London.

Walzer, M (1983) Spheres of justice: A defence of pluralism and equality. Blackwell, Oxford.

Young, MD (1958) The rise of meritocracy. Thames \& Hudson, London. 